\title{
Investigação dos padrões relacionais do vínculo mãe-filha envolvidos na obesidade feminina
}

\author{
Investigation of the relationship patterns of the mother- daughter \\ bond involved in female obesity
}

\author{
Paula Pereira Teodoroํㅜ, Tatiane Mitsue Koga ${ }^{1}$, Maria Vilela Pinto Nakasu²
}

Teodoro PP, Koga TM, Nakasu MVP. Investigação dos padrões relacionais do vínculo mãe-filha envolvidos na obesidade feminina / Investigation of the relationship patterns of the mother-daughter bond involved in female obesity. Rev Med (São Paulo). 2017 abr.jun.;96(2):63-72.

RESUMO: Introdução: A obesidade apresenta uma incidência elevada e gênese multifatorial, como fatores biológicos, ambientais e psicológicos. Dentre os psicológicos, os conflitos na relação mãe-filha podem contribuir para a gênese da obesidade feminina. Objetivo: O objetivo desse estudo é investigar os padrões relacionais do vínculo mãe-filha envolvidos na obesidade feminina. Materiais e Métodos: Foi realizado estudo transversal, qualitativo, com pacientes obesas do Programa de Cirurgia Bariátrica de um Hospital Escola do Sul de Minas Gerais. Todas possuíam IMC acima de $30 \mathrm{~kg} / \mathrm{m}^{2}$ e eram maiores de 18 anos. A determinação da amostra foi de 12 pacientes, número suficiente para se atingir a saturação (Field Methods). Foram realizadas as entrevistas não-diretivas, gravadas e transcritas para análise posterior segundo a Metodologia de Análise de Conteúdo de Bardin. Resultados e Discussão: Foram encontradas seis temáticas centrais relacionadas à influência do vínculo mãe-filha sobre a obesidade feminina: comida/fuga/prazer; ganho de peso após a gravidez; superproteção/dominação materna; abandono materno; abuso sexual; insegurança/baixa autoestima/depressão. Conclusão: Foi possível evidenciar uma relação entre conflitos na relação mãe-filha e condições para a gênese da obesidade.

Descritores: Psicologia; Obesidade/psicologia; Transtornos da alimentação e da ingestão de alimentos/psicologia; Apego ao objeto; Relações mãe-filho/psicologia.

\begin{abstract}
Introduction: Obesity has a high incidence and multifactorial genesis, such as biological, environmental and psychological factors. Among the psychological factors, the conflicts in the mother-daughter bond can contribute to the genesis of female obesity. Objective: The objective of this study is to investigate the relationship patterns of the mother-daughter bond involved in female obesity. Materials and Methods: A crosssectional, qualitative study with obese patients in the Bariatric Surgery Program in a Hospital in Minas Gerais. All them have had BMI over $30 \mathrm{~kg} / \mathrm{m}^{2}$ and were older than 18 years of age. The determination of the sample of 12 patients was sufficient for achieving saturation (Field Methods). The interviews were nondirective ones, recorded and transcribed for posterior analysis according to Bardin's content analysis methodology. Results and Discussion: Six main themes were found and related to the influence of the mother-daughter bond on female obesity: Food / escape / pleasure, Overprotection/ Maternal domination, Maternal Abandonment, Sexual abuse, low self-confidence / low selfesteem / depression, weight gain after pregnancy. Conclusion: It was possible to show a significant relationship between conflicts in the mother-daughter relationship and conditions for the genesis of obesity.
\end{abstract}

Keywords: Psychology; Obesity/psychology; Feeding and eating disorders/psychology; Object attachment; Mother-child relations/ psychology.

Agradecemos à FAPEMIG pelo apoio na forma de concessão de bolsa de Iniciação Científica.

1. Acadêmica do Curso de Medicina da Faculdade de Medicina de Itajubá FMIT/MG. E-mail: paulapteodoro@yahoo.com.br, tatiane. mkoga@yahoo.com.br.

2. Prof. Dr. da Faculdade de Medicina de Itajubá FMIT/MG. E-mail: mvilelanakasu@gmail.com.

Endereço para correspondência: Paula Pereira Teodoro. Av. Renó Júnior, 368 - São Vicente. Itajubá, MG. CEP: 37502-138. 


\section{INTRODUÇÃO}

obesidade é conceituada como uma doença crônica que gera um acúmulo excessivo de gordura corporal em um indivíduo, podendo representar riscos à saúde ${ }^{1,2}$. Esse processo ocorre por meio de uma ingestão calórica que excede o gasto de energia do organismo, resultando em um desequilíbrio do balanço energético e consequente acúmulo de tecido adiposo no corpo $^{2,3}$.

A obesidade já adquiriu caráter epidêmico devido ao crescimento de sua incidência no mundo nos últimos anos, por essa razão, a Organização Mundial de Saúde (OMS) considera essa patologia uma questão de Saúde Pública ${ }^{2,5}$. O critério utilizado pela OMS para diagnosticar a obesidade é o Índice de Massa Corporal (IMC), calculado pela razão entre o peso e a altura elevada ao quadrado ${ }^{4,5}$.

No Brasil, o número de pessoas obesas é próximo de 18 milhões, porém, somando o total daqueles considerados acima do peso este número sobe para 70 milhões, o que equivale a quase $40 \%$ da população total ${ }^{1,4}$. Nas duas últimas décadas, houve um aumento de $240 \%$ no índice de obesidade entre crianças e adolescentes segundo a OMS e Organização Pan-Americana de Saúde (OPAS) ${ }^{4,5}$.

O estudo da obesidade é complexo devido a sua gênese multifatorial, como fatores biológicos, ambientais e psicológicos, que podem estar associados ou agir independentemente ${ }^{4}$. Pesquisas revelam que, dentre os fatores biológicos, há maior influência de fatores genéticos e da hereditariedade na predisposição à obesidade em pessoas do sexo feminino. Para que a patologia em questão se manifeste, no entanto, é necessário que fatores ambientais favoráveis à obesidade estejam igualmente presentes ${ }^{6}$.

A partir do final do século XX, baseando-se na ideia de que o corpo e a mente se correlacionam, a obesidade tem sido considerada uma doença psicossomática, que envolve um desajustamento emocional ${ }^{4,7}$. Nesse sentido, estudos sugerem que a excessiva ingestão de alimentos seria influenciada por fatores psicológicos, dentre os quais, o receio de sofrer privações, a reação a uma frustração (perda e/ou separação) ou, até mesmo, a necessidade de ser amado $^{4,8,9,10}$. A obesidade poderia estar igualmente relacionada a uma fixação na fase oral do desenvolvimento psicossexual, tal como proposto por Freud? ${ }^{7}$.

$\mathrm{O}$ vínculo mãe-filha, definido como relação de afeto, pode interferir positiva ou negativamente no estado nutricional da filha ${ }^{9,11}$. $\mathrm{O}$ excesso de proteção nesta relação pode acarretar consequências negativas aos hábitos alimentares. Frente a uma postura de superproteção materna, a obesidade resultaria em uma forma de defesa encontrada diante da experiência de desamparo provocada pela separação da mãe. Vínculos de dependência na relação mãe-filha (relação simbiótica) produziriam, deste modo, reações emocionais que conduziriam a modificações na forma física; a gordura da filha, simbolicamente, representaria a proteção materna ${ }^{4,9,12,13,14}$.

A obesidade também tem sido relacionada, pela literatura especializada, às experiências de rejeição materna. Nesse sentido, a ingestão excessiva de alimento funcionaria como negação aos conflitos interpessoais e impediria o confronto com as questões ligadas ao abandono. $\mathrm{O}$ ato compulsivo de comer encobriria, portanto, o fracasso na relação com a mãe. Por sentir-se rejeitada, a filha voltaria sua agressividade contra si mesma, castigando seu próprio corpo por meio da alimentação excessiva ${ }^{4,8,12,14}$. Considerando-se que a obesidade é uma questão de saúde pública, e tendo em vista o aumento expressivo desta patologia no Brasil, torna-se relevante a produção de estudos nesta área.

Com o propósito de contribuir para a compreensão dos fatores emocionais envolvidos na produção do transtorno alimentar da obesidade feminina, este estudo se propõe a identificar aspectos psicológicos da relação mãe-filha relacionados à gênese desta doença. Buscase, deste modo, ampliar o conhecimento científico a respeito dos fatores envolvidos na obesidade e auxiliar no aprimoramento das modalidades de intervenção junto à população. Essa pesquisa apresenta, portanto, o objetivo de investigar os padrões relacionais do vínculo mãe-filha envolvidos na obesidade feminina.

\section{MATERIAIS E MÉTODOS}

O presente estudo, transversal, de abordagem qualitativa, foi realizado pela produção de base empírica por meio do trabalho de campo junto a 12 pacientes obesas que participavam do Programa de Cirurgia Bariátrica de um Hospital Escola do Sul de Minas Gerais no ano de 2015. Esse programa conta com uma equipe multiprofissional composta por enfermeiros, psicólogos, nutricionistas e médicos, e existe desde agosto de 2014. Todas as participantes possuíam IMC acima de $30 \mathrm{~kg} / \mathrm{m}^{2}$ e eram maiores de 18 anos.

Considerando-se que, nas pesquisas qualitativas, não se calcula o tamanho da amostra, em um estudo da "Field Methods", Guest et al. ${ }^{15}$ propôs que 12 entrevistas eram suficientes para chegar à saturação ${ }^{15,16}$. A determinação da amostra foi, portanto, de 12 pacientes inicialmente, e se necessário, o tamanho da amostra seria aumentado até que se alcançasse a saturação. No tipo de amostragem por saturação, o pesquisador identifica que a partir de um determinado ponto (ponto de saturação) começa haver repetição de informações obtidas dos sujeitos da pesquisa e tal repetição não traz acréscimos significativos à pesquisa, começa a existir redundância nas respostas obtidas e, a partir desse ponto, o pesquisador encerra a amostragem ${ }^{16}$. Para evitar dificuldades técnicas para uma constatação objetiva da saturação, foi seguida uma sequência de oito passos procedimentais de tratamento e análise de dados 
coletados nas entrevistas, tal como determina Fontanela e Saidel ${ }^{17}$.

A pesquisa foi iniciada apenas após a aprovação pelo Comitê de Ética em Pesquisa (CEP) pelo número CAAE: 37122214.8.0000.5559. A abordagem das participantes partiu de um convite informal dos pesquisadores, foram expostos os objetivos do trabalho e esclarecidas possíveis dúvidas. Com a aderência por parte dos sujeitos da pesquisa, foram marcados data e horário conveniente para ambas as partes. No dia e hora marcados, foram aplicados o Termo de Consentimento Livre e Esclarecido. Em seguida, foram realizadas as entrevistas não-diretivas que constituem o principal instrumento de coleta de dados nas pesquisas qualitativas no campo da saúde. Para os profissionais de saúde, saber o que as pessoas sentem e imaginam permite uma relação mais adequada com o paciente ${ }^{18}$.

As entrevistas não-diretivas foram orientadas de acordo com três temáticas: Histórico da doença, Dinâmica familiar e Comportamento emocional, e permitiram que as participantes ficassem livres para externar e discutir questões ligadas às modalidades de relações com suas mães. As entrevistas foram gravadas e transcritas para posterior análise.

Os dados coletados foram analisados segundo a metodologia de análise de conteúdo de $\operatorname{Bardin}^{19}$. A técnica da análise temática é adequada à investigação qualitativa do material sobre saúde ${ }^{16}$. As diferentes fases da análise de conteúdo organizaram-se em torno de três polos, conforme Bardin $^{19}$ : 1) A pré-análise; 2) A exploração do material, por meio de contato exaustivo com esse, e 3) O tratamento dos resultados: a inferência e a interpretação. Tal procedimento permitiu descrever o conteúdo das mensagens, levantar indicadores qualitativos que levaram à inferência de conhecimentos relativos à influência do vínculo mãe-filha na determinação do transtorno alimentar da obesidade ${ }^{19}$.

\section{RESULTADOS}

Foi possível chegar, por meio dessa metodologia, a seis temáticas centrais relacionadas no quadro abaixo:

Quadro 1. Temáticas centrais encontradas nas entrevistas nãodiretivas

\begin{tabular}{|l|c|}
\hline Comida/fuga/prazer & $83,3 \%$ das entrevistadas \\
Ganho de peso após gravidez & $58,3 \%$ das entrevistadas \\
$\begin{array}{l}\text { Superproteção/dominação } \\
\text { materna }\end{array}$ & $41,6 \%$ das entrevistadas \\
$\begin{array}{l}\text { Insegurança/baixa autoestima// } \\
\text { depressão }\end{array}$ & $25 \%$ das entrevistadas \\
Abandono materno & $25 \%$ das entrevistadas \\
Abuso sexual & $16,6 \%$ das entrevistas \\
\hline
\end{tabular}

Com o propósito de validação do processo de análise, foi realizada, em conjunto com a orientadora, revisão do conteúdo das entrevistas e das unidades temáticas identificadas, para assegurar que os achados representavam as experiências das informantes.

Foram respeitados os procedimentos éticos para pesquisas com seres humanos, contidos na Resolução 196/96, do Conselho Nacional de Saúde.

As seis temáticas centrais, encontradas nas entrevistas e relacionadas à influência do vínculo mãe-filha sobre a obesidade feminina, foram:

Comida/fuga/prazer: aparece em $83,3 \%$ das falas. V.A.S.P., diz, por exemplo:

“... mas a gente gosta de comer. A gente associa muito comida a prazer. Cultura de família mesmo. Meu irmão ia chegar, minha mãe fazia mil coisas para esperar. Empadão, rosca... Eu sou muito assim... É isso que estou trabalhando agora ... Não precisa comer tanto".

A associação alimento/prazer tem se mostrado consensual na literatura especializada ${ }^{20,25}$;

Ganho de peso após gravidez-Superproteção/ dominação materna: referência que aparece em 41,6\% das entrevistas. V.C.T. afirma, a esse respeito:

"Superprotetora. Agora ela já está desencanando. Meus pais sempre foram muito superprotetores com a gente. Ela sempre foi muito presente, desde a infância. Sempre, sempre. Em tudo. Vixi, tudo. Escola, reunião, tarefa. Tudo. Bem mais que meu pai, porque ele estava sempre trabalhando. Então era ela, o carro chefe de tudo".

A percepção da presença maciça da mãe, "sufocante", associada à gênese da obesidade, pode ser encontrada em análises psicológicas de orientação psicanalítica. Nesse sentido, o invólucro de gordura é considerado uma capa protetora imaginária ${ }^{26,27}$;

Insegurança/baixa autoestima/depressão: foi identificada em $25 \%$ das falas. V.A.S.P. expressa esta ideia da seguinte forma:

"Eu me sentia amada, especial e valorizada. Passei a viver sozinha e me sentindo rejeitada, sem valor nenhum".

Experiências precoces de excesso e falta de amparo maternos parecem favorecer a estruturação de dinâmicas psíquicas frágeis do ponto de vista do investimento narcísico, daí surgem queixas como as de insegurança, e auto-depreciação ${ }^{28,30}$;

Abandono materno: apareceu em 25\% das entrevistas. L.A.R. afirma, por exemplo:

"Eu senti como se a minha mãe tivesse me abandonado... Eu senti como se ela tivesse largado, entendeu? Para viver a vida dela, porque ela realmente não se preocupou".

Privação da figura materna como fator predisponente ao mecanismo psíquico da compulsão alimentar: esta ideia tem sido amplamente discutida no campo de tratamento dos 
Teodoro PP. Investigação dos padrões relacionais do vínnculo mãe-filha envolvidos na obesidade feminina.

Transtornos Alimentares ${ }^{31,33}$;

Abuso sexual: apareceu como tema em $16,6 \%$ das entrevistas. A.P.A afirma, por exemplo:

"Esteticamente falando, eu acho que isso foi até um refúgio para mim. Porque assim, ninguém olha, ninguém quer".

A relação entre o abuso sexual e distúrbios alimentares tem sido extensamente pesquisada ${ }^{34,35}$.

\section{DISCUSSÃO}

\section{Comida/fuga/prazer}

Estudos sugerem que a comida tem um significado bastante complexo para os indivíduos obesos. Ela pode estar associada a uma forma de compensação por uma frustração ou afetos que a pessoa não sabe identificar. A comida assume, como sugere $\mathrm{Kaufman}^{8}$, caráter de um ato desprovido de reflexão, um ato automotivo. Ela pode representar a fuga de problemas emocionais ou conflitos interpessoais, na tentativa de obter um alívio para si mesmo ou o mascaramento desses problemas. O presente estudo identificou um número expressivo $(83,3 \%)$ de referências, durante as entrevistas, em relação à questão comida/fuga/ $\operatorname{prazer}^{20}$.

De outro modo, a comida pode assumir o sentido de uma experiência prazerosa na medida em que, por meio dela, a união de familiares ou amigos e o fortalecimento de vínculos afetivos podem se dar ${ }^{21,22}$. Culturalmente, a comida pode representar celebração, festividade e união familiar. Juntar-se ao redor da mesa com os familiares para saborear uma refeição adquire, nesse sentido, um significado de felicidade e plenitude ${ }^{21,22}$. No depoimento de V.C.T. é possível identificar, a um só tempo, um elemento compulsivo, isto é, o ato de comer sem reflexão, e o elemento propriamente ritualístico ou cultural que pode assumir a comida quando em coletividade.

"Igual eu falei assim, é prazer de comer. É um prazer momentâneo que depois eu meio que me arrependo. Mas vamos comer, porque está gostoso. Sei lá o porquê. Eu não sei se é cômodo, você sentar e comer para bater um papo. Representa familia".

O ritual de comer é vivenciado como uma experiência de extremo prazer, uma vez que, ao sentar em torno da mesa, a família se une, troca afeto. Há, contudo, a percepção por parte da entrevistada de um limite que é desconsiderado. Tal parece ser a necessidade de perpetuar esse momento de satisfação que o ato de comer segue em um continuo absoluto. Trata-se de comer para obter prazer oral e igualmente suprir ou compensar um sentimento de vazio. Assim, diz, outra entrevistada, V.C.T.:

"Porque lá em casa tudo se resume em sentar para comer todo mundo junto. Comemorar alguma coisa. Ou vamos comer porque eu estou mal. Vou fazer um bolo para agradar o fulano. Sabe assim? É tudo resumido na comida. Reunir a família para sentar e comer".

$\mathrm{O}$ alimento pode suprir uma falta emocional e apaziguar a angústia. Segundo Fedida ${ }^{24}$, a consumação de guloseimas pode ser também interpretada como uma compulsão de compressão interior de objetos, a fim de evitar que apareça um vazio. A semiologia do fantasma é aqui extremamente simbólica e variada. Ela coloca em jogo, na cura, a problemática da incorporação, assegurando, ao conteúdo alimentar, a ambivalência de um efeito reparador e destruidor, ou ainda, gratificante e persecutório. Angústia, culpabilidade e autoagressividade aparecem na seguinte passagem da entrevista de J.O.S:

"Ai eu comia, respirava um pouco, ia lá e comia de novo...
Ai depois de um tempo, eu comia bastante, mas eu ficava
com raiva porque eu tinha comido, ai eu comia de novo
porque eu estava com raiva".

Nesse trecho, pode-se perceber a angústia gerada ao comer excessivamente para tentar escapar do sofrimento, porém, essa atitude acaba gerando um forte sentimento de culpabilidade. Surge, assim, um círculo vicioso do qual a paciente não consegue se libertar: sofrimento-comidaculpa-comida.

Além da problemática da falta associada à culpa e agressividade é possível relacionar a falta e o alimento ao ato compulsivo de comer. Campos ${ }^{25}$ retoma a tese de Lacan acerca do ressecamento do leite no seio materno, a qual pode ser relacionada aos casos de gula.

Uma vez fixado na pulsão oral, o glutão, em vez de desejar, deixa-se enganar pela demanda localizada no alimento que faz as vezes do objeto perdido. O sujeito parece gozar não com aquilo que ele come, mas do impulso a comer, semblante daquilo que falta ao sujeito irremediavelmente $(\mathrm{p} .32)^{25}$.

O gozo parece se localizar na vontade de comer, na avidez com que se espera ou busca o alimento, e menos no ato de sugar, mastigar, deglutir, ingerir ou na sensação de plenitude gástrica ${ }^{24,36}$.

\section{Ganho de peso após gravidez-superproteção-dominação materna}

O corpo tem sido objeto privilegiado de investimento libidinal na contemporaneidade: sua exposição estética, a rigidez do padrão de beleza vigente, ideais de perfeição e do culto a magreza tornam a questão do corpo extremamente atual. É na ligação com o somático, no registro propriamente corporal, que manifestações psicopatológicas aparecem. $\mathrm{O}$ corpo não é imune à história. Como observa Volich ${ }^{29}$,

... muitas vezes, diante do sofrimento e da perda, entre o
vazio e a palavra, o corpo se vê convocado. Inscrevem-se
ali os prazeres, os encontros felizes e gratificantes, mas
também as dores, as perdas, as separações, mais difíceis
de serem compartilhadas. Entre o real e o imaginário,
inclina-se muitas vezes o corpo à exigência de conter o 
Teodoro PP. Investigação dos padrões relacionais do vínnculo mãe-filha envolvidos na obesidade feminina.

sofrimento indizível, de suportar a dor impossível de ser representada (p.10).

Em que sentido o corpo pode ser o depositário de frustrações e conflitos na relação com a figura materna? Os resultados deste estudo corroboram com essa suposição. As implicações subjetivas da relação mãe-filha nos quadros de obesidade têm sido alvo de inúmeros estudos no campo psicanalítico. $\mathrm{O}$ comer compulsivo pode revelar o estresse da relação com a mãe. Fenichel ${ }^{30}$ associa a origem da obesidade a uma dependência excessiva da mãe, sobretudo a presença de uma mãe superprotetora nas primeiras modalidades de relação junto ao filho recém-nascido.

Para Nóbrega e $\mathrm{Spada}^{27}$, o vínculo afetivo hostil nas relações mãe-filha é geralmente observado no tratamento psicanalítico com obesas. De acordo com os autores, à medida em que a criança cresce e desenvolve novas habilidades, a sua interação com o ambiente possibilita que ela adquira maior autonomia em relação à mãe, aprimorando gradativamente suas competências e proporcionando confiança em si mesma. No entanto, isso pode resultar em uma mudança no vínculo com a mãe: tal mudança pode ser vivenciada pela mãe como uma perda da qualidade prazerosa da relação entre as duas. Diante dessa situação, a mãe pode tentar adiar o desapego da filha, adotando atitudes de superproteção. O excesso com os cuidados alimentares da criança, a fim de sentir que a filha está sendo bem cuidada, inclui-se igualmente como um comportamento superprotetor ${ }^{13,26,27,37}$.

Nas entrevistas realizadas foram numerosas $(41,6 \%)$ as referências à imagem de uma mãe superprotetora e dominadora. No depoimento de M.M.R.M, encontra-se a seguinte descrição:

"A imagem que eu tenho da minha mãe é o meu tudo. Até hoje, acho que não sai de casa, porque eu tenho condição de morar sozinha, mas eu não saí por esse laço que eu tenho".

Segundo Zimerman ${ }^{37}$, a mãe simbiotizadora não renuncia ao desejo de uma eterna gravidez, ela toma a posse de seu filho, assumindo-o como um mero prolongamento do seu narcisismo. Ela delega ao filho o poder de representar o falo que ela almeja.

A superproteção igualmente pode ocorrer devido à tentativa da mãe de encobrir uma rejeição anterior; o que pode ser expresso por meio de cuidados alimentares exagerados. Quanto mais a criança engorda, mais decepção provoca na mãe, que acaba se tornando agressiva. Porém, posteriormente, a mãe é invadida por um sentimento de culpa e tenta compensar o desafeto com alimentos pelo fato de não conseguir lidar com seus sentimentos de outra maneira. Forma-se, assim, um círculo-vicioso: rejeição-alimento excessivo-obesidade-rejeição. Contudo, o alimento não supre a criança integralmente, já que ela não recebe o afeto de que necessita. Desse modo, apesar de se alimentar, permanece um sentimento de vazio na criança, que pode gerar a compulsão alimentar. Este mecanismo pode se refletir na vida adulta, na medida em que a inabilidade para lidar com as emoções por meio do pensamento tenderá a gerar saídas sintomáticas pela via do somático. $\mathrm{Na}$ impossibilidade de elaborar seus próprios sentimentos, a filha recorre à comida para saciar suas angústias ${ }^{37}$.

Desde a infância até a vida adulta, a filha tende a perceber gradativamente a importância vital da mãe, o que pode resultar em um medo de perdê-la ou desagradála. Isto pode gerar a necessidade de substituir o afeto por alimentação excessiva. A ansiedade pode advir, nesse caso, pelo fato de a filha, presa a uma relação de dependência, nunca se sentir apta a enfrentar sozinha as experiências de frustração do cotidiano. Essa situação conflitante pode impulsionar a ingesta de alimentos, podendo culminar na obesidade $^{27,33}$. Este aspecto da relação junto à mãe pode ser ilustrado pela passagem do depoimento de R.S.S.L:

"Eu acredito que, no meu inconsciente, a falta dela tem ajudado nessa ansiedade. No exagero da alimentação".

Durante o período da gravidez é comum a mulher passar por um momento de grande ansiedade, pois além das mudanças corporais, mudanças psíquicas e sociais acontecem podendo mobilizar defesas emocionais arcaicas. Nesta fase, a mulher abandona o status de filha, passando a desempenhar o papel de mãe. A qualidade do vínculo da grávida com seus genitores, em particular com sua própria mãe, nas fases mais precoces da vida, desempenha papel decisivo no curso da gestação atual. Foi expressivo $(60 \%)$ o número de falas que evidenciam uma correlação entre gravidez e posterior ganho de peso, possibilitando o surgimento da obesidade ${ }^{38}$.

A obesidade adquirida após a gravidez pode igualmente estar relacionada a uma desaceleração das atividades habituais em virtude de novas responsabilidades, como cuidar da família e, principalmente, do filho recémnascido. Isso configura uma mudança significativa nos hábitos sociais, que pode elevar o grau de ansiedade, culminando em isolamento social e excessiva ingesta alimentar $^{39}$. A seguinte passagem corrobora esta relação:

"Eu comecei a viver muito em função dele, eu seguia os horários dele, os ritmos dele, então eu comia na hora que dava tempo, eu comia muita bobeira, porque era o que era mais rápido e eu fiquei um ano e três meses só aqui dentro de casa com ele", disse L.A.R.

R.S.S.L também menciona, a esse respeito:

“(...) foi depois que eu tive meu segundo filho. Daí, depois da gravidez dele eu não perdi. Eu abri mão de tudo, eu trabalhava, as crianças tinham escola em periodo integral. Ai, viemos para Itajubá. Ansiedade de novo. Não conhecia absolutamente ninguém".

Reforçando a ideia de que a qualidade do vínculo da grávida com seus progenitores interfere significativamente na relação com seu bebê, Dias e Monteiro ${ }^{30}$ afirmam que 
a capacidade de uma mãe estar com o seu bebê depende da sua identificação primária com ele, e esta, por sua vez, depende da própria capacidade de se identificar com o bebê que ela já foi. Haveria, pois, uma relação entre as mães que se tornam obesas com uma deficiência afetiva junto a suas próprias mães, no passado.

$\mathrm{O}$ que dizer da figura paterna no interior desta discussão acerca da relação mãe/filha na gênese da obesidade? Ora, é consensual o fato de que a participação efetiva da presença paterna na vida da criança desde o início da sua existência, com funções variadas, possibilita seu desenvolvimento emocional. Além de o pai ser um dos pilares do triângulo edípico, o pai, antes de surgir como terceiro já se faz necessário à vida da dupla mãe-bebê na medida em que sustenta essa relação ao oferecer um tipo especial de "holding" à mãe; contingência que protege-a das influências externas e cria condições para que ela possa devotar-se ao bebê $\hat{e}^{38}$.

No estágio do concernimento ou rumo à independência, o pai entra definitivamente na vida da criança como uma terceira pessoa, uma figura forte e protetora, que contém a destrutividade de seus impulsos amorosos primitivos em relação à mãe. Isto permite à criança vivenciar suas potências destrutivas sem medo de destruir a figura materna. "Assim, o pai constitui a representação de um ambiente indestrutível, responsável por dar continuidade ao processo de desilusão iniciado pelos fracassos adaptativos da mãe" ${ }^{40}$.

A imagem paterna presente nas entrevistas relaciona-se a um pai que não oferece suporte suficiente para promover os cuidados básicos das filhas e igualmente sua autonomia, ou ainda, não apoia a figura materna no exercício desta função. Diante da falha da função paterna, há o risco de se perpetuar a dependência materna, dificultando o acesso do filho à vivência triangular e edípica. Estudo realizado com pais de crianças obesas em Centro de Saúde de Ribeirão Preto apontou para conflitos importantes na relação pai/filho, como incapacidade de perceber o progenitor de forma completa e integrada, perdidos em suas funções. A pesquisa aponta para tentativa de compensação do pai mediante exercício demasiado austero da autoridade. A figura paterna, nesta pesquisa, algumas vezes, foi vista como aquela que ora sustentava a criança e oferecia força e apoio, e como aquela que abandonou os cuidados da filha. A relação da mãe com o pai foi descrita sempre como uma relação conflituosa ${ }^{40}$. A entrevistada M.A.F.M, a esse respeito, afirma:

"Meu pai e minha mãe se separaram quando eu era muito criança, eu tinha 10 anos, então isso também pode ter ajudado \{\{no ganho de peso\}\}, era uma fase que eu precisava dele né? Foi dificil pra mim nessa época".

Ela continua:

"Meus pais sempre brigavam e eu estava junto, e meu pai ia para o bar e eu ia com a minha mãe buscá-lo. Então, por tudo isso era um alivio a separação, mas ao mesmo tempo não era, porque a gente não ia ter nosso pai lá. Era um conflito muito grande." J.O.S diz: "Eu fiquei sabendo que meu pai morreu depois de três meses. Por que não me contaram? Por que tanta ruindade? Ninguém me falou".

Para J.O.S, o vínculo se mantinha, mas o contato era sempre prenhe de conflito e tensão. Ela diz:

“... tentei muito me aproximar dele escondido, porque lá onde a gente morava, eles falavam que se eu fosse atrás dele eu ia apanhar. Ás vezes, eu matava aula a tarde pra ir pra casa dele. Várias vezes eu tentei contato com meu pai, falava que queria morar com ele, só que meu pai, cada tempo tinha uma mulher diferente...Eu não sei explicar o que eu sentia, mas eu gostava".

\section{Abandono materno}

Segundo Dixon ${ }^{41}$, a obesidade pode estar relacionada à condições socioculturais e emocionais que podem afetar o crescimento, o desenvolvimento e o estado nutricional da criança. Nesse sentido, a fragilidade no vínculo mãe/ filha pode atuar como importante fator predisponente ao surgimento do transtorno alimentar. A criança privada do afeto da mãe, seja pela indiferença emocional ou pelo abandono materno propriamente dito pode nutrir um sentimento de desamparo que, a curto ou longo prazo, pode acarretar distúrbios emocionais que podem levar à compulsão alimentar e, consequentemente, à obesidade ${ }^{43}$.

A tarefa da mãe é, para Winnicot ${ }^{38}$, garantir ao bebê que ele estará sempre protegido das perturbações do ambiente. As perturbações que não ultrapassam o tempo e a capacidade do bebê para lidar com elas, tendem a não interromper o amadurecimento e são importantes para que ele desenvolva seus próprios recursos. No entanto, se as perturbações ultrapassam a capacidade de maturação do lactente, podem produzir reações que, por acontecerem em um estágio inicial, podem vir acompanhadas de uma perda temporária da identidade em formação. A privação afetiva decorrente da indiferença materna pode ocorrer devido à emergência de um problema psicopatológico da mãe, como depressão pós-parto ou privação por abandono ou rejeição. Frente a um relacionamento entre mãe e filha desvitalizado, a onipotência da criança, essencial para a formação de sua identidade, é abalada, uma vez que o ambiente passa a ser ameaçador e hostil. Com vistas a restabelecer um vínculo onipotente e a satisfazer um desejo que possa ser atendido prontamente, o ato compulsivo de se alimentar pode ser considerado uma saída psíquica ${ }^{38}$.

Por outro lado, segundo Berg e Dalgalarrondo ${ }^{39}$, o abandono pode criar uma situação em que a criança cresce sem carinho, amor e amparo maternos, facilitando o surgimento de distúrbios emocionais que levam à compulsão alimentar. Diante dessa situação, a filha, defasada de amor, encontra no comer em excesso, um mecanismo de defesa utilizado para encobrir sentimentos inconscientes de abandono e desamparo. O indivíduo 
Teodoro PP. Investigação dos padrões relacionais do vínnculo mãe-filha envolvidos na obesidade feminina.

obeso, na tentativa de dissipar sentimentos de angústia, raiva, culpa, depressão ou qualquer outro estado afetivo que dê origem a uma tensão psíquica insuportável, lançaria mão de um comportamento, o qual Mc Dougall denomina comportamento aditivo. A comida, portanto, eliminaria qualquer tensão (que pode incluir afetos prazerosos) que originam sentimentos de excitação percebidos como proibidos ou perigosos. Comer, assim, atenuaria esta modalidade de vivência emocional. Acerca do abandono materno J.O.S. comenta:

“Minha mãe largou a gente lá... Deixou a gente lá para ver um negócio no serviço, falou que ia buscar a gente e não buscou mais (...) Hoje eu cuido dela, porque sou filha, eu tenho a obrigação de cuidar, mas no fundo, no fundo, eu acho que eu não tenho obrigação de cuidar sabe? Eu não chamo ela de mãe, porque eu não consigo chamar ela de mãe. Igual dia das mães, eu não consigo dar um abraço nela e ela também não consegue muito se aproximar de mim". "Acaba que a comida é o que sacia aquela coisa que está incomodando”, diz V.C.T.

Tais exemplos apontam para uma correlação entre desamparo e desafeto maternos como produtores de um vazio interno e consequente compulsão alimentar ${ }^{41-43}$.

\section{Abuso sexual}

McDougall ${ }^{40}$, em seu livro "As múltiplas faces de Eros" (1995), apresenta algumas considerações sobre o conceito de "economia adictiva". Esse comportamento pode advir de "um ato que carrega a ilusão de fazer algo para ajudar a si mesmo em meio às dificuldades da vida cotidiana". "Adicção" refere-se a um estado de escravidão do indivíduo. O objeto adictivo é considerado algo bom que pode conferir significação à sua vida. Nesse sentido, o objeto adictivo assume a função de amenizar sentimentos de culpa, depressão, raiva, angústia ou qualquer outro estado afetivo que levem a tensões psíquicas. Os comportamentos adictivos podem se manifestar por meio de práticas como, beber ou comer excessivamente, uso de drogas ou, até mesmo, busca incessante por sexo, entre outros ${ }^{40}$.

Relacionando o conceito de "economia adictiva" ao vínculo mãe-filha, pode-se retomar as ideias de Winnicott pode-se afirmar que o prolongamento excessivo do período em que mãe-bebê constituem uma unidade, pode gerar uma interação patológica com o bebê, prejudicando o desenvolvimento de recursos psíquicos que o permita lidar com situações de tensão. Desse modo, o bebê busca sempre, na figura da mãe, o suporte para lidar com quaisquer situações de estresse emociona9. Porém, à medida em que a filha cresce, devido às próprias vivências cotidianas, a relação simbiótica mãe-filha tende naturalmente a diminuir: como a filha é incapaz, psicologicamente, de solucionar sozinha questões internas, encontra em objetos externos (adictivos), como a comida, a representação da função materna $^{40}$.
Uma relação conflitante com a mãe pode resultar em uma predisposição à compulsão alimentar, prejudicando o referencial de feminilidade. Em outros termos, a gordura substitui a feminilidade da filha, uma vez que distorce sua imagem corporal e abala sua sexualidade; seu corpo não corresponde mais aos padrões de beleza impostos pela sociedade ${ }^{41,42}$

Godoy $^{34}$ identifica uma relação entre obesidade e abuso; a obesidade entendida como um recurso adictivo de proteção contra o objeto sexual que elas representam. Com isso, pode ocorrer uma neutralização da identidade sexual da mulher, e consequente refúgio por detrás de suas camadas de gordura. A gordura representaria, portanto, uma barreira de proteção contra os "perigos" que o corpo, como objeto sexual, poderia proporcionar. A temática do abuso sexual apareceu em $16,6 \%$ das falas, achado que chamou atenção. J.O.S revelou, por exemplo:

“...eu era molestada, eu fui abusada quando eu tinha dez anos e continuou até certo tempo.... Isso me marcou muito, porque eu não esqueço".

Posteriormente, a mesma entrevistada afirma:

"Eu sou gorda e ninguém vai olhar para mim...",

demonstrando ter encontrado, na obesidade, uma forma de proteção. Outra entrevistada, A.P.A, diz:

"Esteticamente falando, eu acho que isso foi até um refúgio para mim. Porque assim, ninguém olha, ninguém quer".

O abuso sexual pode ser um fator que predispõe a emergência de distúrbios de compulsão alimentar"48.

Para Oliveira e $\mathrm{Narvaz}^{35}$, são heterogêneos os resultados dos estudos que investigam uma possível relação entre abuso sexual e transtornos alimentares. No entanto, a ocorrência de trauma sexual real nos primeiros anos de vida de pacientes que apresentam transtornos alimentares tem sido negligenciada na literatura e na investigação clínica. $\mathrm{O}$ fato de a prevalência de abuso entre as mulheres com transtornos alimentares ser, segundo as autoras, similar às taxas encontradas em outros grupos psiquiátricos e na população geral pode se basear em níveis inapropriados de análise da complexidade do fenômeno do abuso sexual, em imprecisões conceituais e no inadequado diagnóstico do abuso e dos distúrbios alimentares. Tal relação precisa ser mais bem explorada.

\section{Insegurança/baixa autoestima/depressão}

Para Tavares et al. ${ }^{49}$, a interação da criança com seus pais é extremamente importante para o desenvolvimento futuro do conceito de si mesma. A conduta materna, desde que transmita segurança à filha, torna-a gradativamente mais confiante. Caso isso não aconteça, a tendência é a filha se tornar insegura e frágil. Em função da dualidade dessa relação que a autoestima da filha poderá ser afetada. Diante do vínculo mãe-filha fragilizado, a filha poderá 
Teodoro PP. Investigação dos padrões relacionais do vínnculo mãe-filha envolvidos na obesidade feminina.

apresentar tendência a conflitos psíquicos e, com isso, rebaixamento da autoestima. Baixa autoestima tem sido evidenciada em inúmeros estudos como fator de risco ao desenvolvimento de transtornos alimentares, uma vez que a compulsão pela comida atuaria como refúgio aos problemas internos; a obesidade surgiria como uma somatização do sofrimento psíquico ${ }^{49-50}$. Em $25 \%$ das entrevistas foi identificada a temática insegurança-baixa autoestimadepressão. A passagem a seguir revela os aspectos negativos da autoimagem. V.A.S.P diz:

"Eu me sentia amada, especial e valorizada. Passei a viver sozinha e me sentindo rejeitada, sem valor nenhum ".

A construção de uma adequada autoestima depende essencialmente do olhar de apreciação da mãe, uma vez que é a partir do ponto de vista do outro que a criança se enxerga. Se a mãe não atribui à filha seu devido valor, ela tende a não desenvolver um olhar seguro de si mesma. Este fenômeno pode ser ilustrado na fala de R.C.B:

"Ela falava assim: Olha o tamanho que você está, olha o tamanho da sua barriga. Olha que feiura que você está. Sabe? Ela sempre me criticou (...) Ela falava pra mim: Eu queria que você fosse magra" ${ }^{\prime 4}$.

Nas relações de dependência materna o olhar da mãe garante a referência identitária da filha, se o olhar é depreciativo, o aspecto negativo estará presente na autoimagem da filha ${ }^{51,52}$.

\section{CONCLUSÃO}

Por meio da análise das entrevistas e da discussão com achados da literatura, foi possível estabelecer uma correlação entre conflitos na relação mãe-filha e condições para a gênese da obesidade. Observou-se relações de dependência entre mãe e filha e superproteção materna de um lado, e relações de desafeto e abandono materno, de outro. Tais relações são influenciadas por conflitos importantes em relação à figura paterna. As

\section{REFERÊNCIAS}

1. Sociedade Brasileira de Endocrinologia e Metabologia. O que é obesidade [citado 15 set. 2014]. Disponível em: http:// www.endocrino.org.br/o-que-e-obesidade/.

2. Recine E, Radaelli P. Obesidade e desnutrição. Brasília: Universidade de Brasília; 2010. Disponível em: http://bvsms. saude.gov.br/bvs/publicacoes/obesidade_desnutricao.pdf.

3. Vasconcellos SC. Relação mãe-filha e sua influência na gênese da obesidade mórbida - um estudo de caso [Dissertação]. Salvador: Universidade Católica do Salvador; 2005. Disponível em: http://tede.ucsal.br/tde_busca/ arquivo.php? $\operatorname{cod} A r q u i v o=49$.

4. Azevedo MASB, Spadotto C. Estudo psicológico da obesidade: dois casos clínicos. Temas Psicol (Ribeirão Preto). 2004;12(2):127-44. Disponível em: http://pepsic. bvsalud.org/scielo.php?script=sci_arttext\&pid=S1413389X2004000200005. duas modalidades de relação (superproteção e abandono) podem servir como potenciais causadores de conflitos psíquicos, alavancando o desenvolvimento de compulsões alimentares. Na maternidade, a relação mãe/filha se atualiza: a maternidade reenvia à mulher a sua condição de filha e é comum a revivescência de antigos conflitos com a imagem materna. Dificuldade de elaboração de tais conflitos podem gerar estados de ansiedade e predispor atos compulsivos. Foi expressivo o número de pacientes que ganharam peso após a gestação. Foram evidenciadas, igualmente, experiências de abuso sexual, o que atuaram nessas mulheres como importante fator ao surgimento de sentimentos profundos de insegurança, medo e baixa autoestima; tais sentimentos parecem ter contribuído para a emergência de quadros posteriores de compulsão alimentar. A compulsão alimentar adquiriu, nesses casos, o significado de uma barreira de proteção, já que, como estariam na condição de gordas, as mulheres deixariam de representar um objeto atrativo sexual.

Finalmente, a atribuição multifatorial para a gênese da obesidade pode ser estendida às modalidades de conflitos na relação mãe/filha. Este estudo sugere a existência de múltiplas determinações, múltiplas roupagens que assume a relação mãe/filha; roupagens que podem predispor à emergência de quadros de ansiedade em relação aos quais, por meio de mecanismos inconscientes, as pacientes buscaram saídas na excessiva ingesta de alimento: a comida como fuga para os conflitos vividos ou um simples prazer momentâneo para suas insatisfações.

Deste modo, é de extrema relevância que o tratamento da obesidade integre, em sua concepção, as implicações subjetivas da relação mãe-filha. A dimensão do desejo e suas implicações devem ser contrapostas a uma perspectiva marcada pelo discurso normativo e de regulação do excesso do "alimento", presente nos programas de tratamento e prevenção do quadro.

5. Guimarães ACA, Feijó I, Soares A, Fernandes S, Machado Z, Parcias SR. Excesso de peso e obesidade em escolares: associação com fatores biopsicológicos, socioeconômicos e comportamentais. Arq Bras Endocrinol Metab. 2012;56(2):320-34. http://dx.doi.org/10.1590/S000427302012000200008 .

6. Oliveira AMA, Cerqueira EMM, Souza JS, Oliveira AC. Sobrepeso e obesidade infantil: influência de fatores biológicos e ambientais em Feira de Santana, BA. Arq Bras Endocrinol Metab. 2003;47(2):124-32. http://dx.doi. org/10.1590/S0004-27302003000200006.

7. Kelner G. Transtornos alimentares: um enfoque psicanalítico. Estud Psicanal (Belo Horizonte). 2004;(27):33-44. Disponível em: http://pepsic.bvsalud.org/scielo. php?script=sci_arttext\&pid=S0100-34372004000100005.

8. Kaufman A. Obesidade feminina e sexualidade. In: Cordás 
Teodoro PP. Investigação dos padrões relacionais do vínnculo mãe-filha envolvidos na obesidade feminina.

TA. Fome de cão: quando o medo de ficar gordo vira doença: anorexia, bulimia e obesidade. São Paulo: Maltese; 1993. p.83-94.

9. Tassara V. Obesidade na infância e interações familiares: uma trama complexa. Belo Horizonte: Coopmed; 2012.

10. Austin H, Smith K, Ward WL. Psychological assessment of the adolescent bariatric surgery candidate. Surg Obes Relat Dis. 2013;9(3):474-80. http://doi.org/10.1016/j. soard.2012.12.004.

11. Vieira VL, Souza JMP, Cervato-Mancuso AM. Insegurança alimentar, vínculo mãe-filho e desnutrição infantil em área de alta vulnerabilidade social. Rev Bras Saúde Mater Infant. 2010;10(2):238-45. http://dx.doi.org/10.1590/S151938292010000200007.

12. Abreu SP, Magalhães EN. Aspectos da relação mãefilha-pai: influência na ingestão alimentar compulsiva e na recusa determinada. E-scientia. 2009;2(1):90-101. Disponível em: http://revistas.unibh.br/index.php/dcbas/ article/view/139/78.

13. Carlson K. A mãe limitadora ou a rejeitadora. In: Carlson K. À sua imagem: analisando a relação mãe e filha. Trad. Maria S. Mourão Netto. São Paulo: Saraiva; 1993. p.42-72.

14. Lima MAC, Fonseca MA. Os distúrbios alimentares sob o olhar da psicanálise. In: Fonseca JGM. Clínica médica obesidade e outros distúrbios alimentares. Belo Horizonte: Medsi; 2001.

15. Guest G, Bunce A, Johnson L. How many interviews are enough? An experiment with data saturation and variability. Field methods. 2006;18:59-82. doi: $10.1177 / 1525822 X 05279903$.

16. Minayo MCS. O desafio do conhecimento-pesquisa qualitativa em saúde. 11a ed. São Paulo: Hucitec; 2014.

17. Fontanella BJB, Saidel MG. Amostragem em pesquisas qualitativas: proposta de procedimentos para constatar saturação teórica. Cad Saúde Pública. 2011;27(2):389-94. http://dx.doi.org/10.1590/S0102-311X2011000200020.

18. Fontanella BJB, Campos CJG,Turato ER.Coleta de dados na pesquisa clínico-qualitativa: uso de entrevistas nãodirigidas de questões abertas por profissionais da saúde. Rev Latino-Am Enfermagem. 2006;14(5):33-40. http://dx.doi. org/10.1590/S0102-311X2011000222222.

19. Bardin L. Análise de conteúdo. 70a ed. São Paulo: Edições; 2011.

20. Cordás TA, Vallim Jr A, Halpern A, Kaufman A, Araújo BC, Assumpção Jr KB. Fome de cão: quando o medo de ficar gordo vira doença - anorexia, bulimia, obesidade. São Paulo: Maltese; 1993.

21. Felippe FML. O peso social da obesidade [citado 08 mar. 2016]. Disponível em: http://encipecom.metodista.br/ mediawiki/images/7/72/GT7-texto4-_O_peso_social_da_ obesidade-_Flavia.pdf.

22. Mendes IB. A obesidade e suas dimensões psicossociais [Monografia]. Brasília: Centro Universitário de Brasília, Faculdade de Ciências da Saúde; 2005.
Disponível em: http://www.repositorio.uniceub.br/ bitstream/123456789/3032/2/20037760.pdf.

23. Rocha LJLF, Vilhena J, Novaes JV. Obesidade mórbida: quando comer vai muito além do alimento. Psicol Rev. 2009;15(2):77-96. doi: 10.5752/P.16789563.2009V15N2P77.

24. Fedida P. Corps Du vide et espace de séance. Paris: Editions Universitaires; 1977.

25. Campos S, Ferreira RA, Cunha CF. Comida: semblante do objeto. Psicol Rev. 2012;18(1):1. http://dx.doi.org/10.5752/ P.1678-9563.2012v18n1p28.

26. Barros VFR. Mães superprotetoras criam filhos ansiosos. Pediatra Orienta. 2013 [Acesso: 2016 Fev 23]. Disponível em: http://www.pediatraorienta.org.br/maes-superprotetorascriam-filhos-ansiosos/.

27. Nóbrega FJ, Spada PV. Vínculo mãe/filho na obesidade. In: Nóbrega FJ. Vínculo mãe/filho. Rio de Janeiro: Revinter; 2005. p.115-34. http://dx.doi.org/10.1590/S1415790X2011000400010.

28. Capitão CG, Tello RR. Traço e estado de ansiedade em mulheres obesas. Psicol Hosp (São Paulo). 2004;2(2):5477. http://dx.doi.org/10.1590/S1516-44462002000400004.

29. Volich MR. O inconsciente, do corpo à palavra. In: Hipocondria: impasses da alma, desafios do corpo. São Paulo: Casa do Psicólogo; 2002. p.146.

30. Güenter R. A obesidade feminina. Analise Psicolol. 2000;18(1):59-70. Disponível em: http://www.scielo.mec. pt/pdf/aps/v18n1/v18n1a05.pdf.

31. Luiz AMAG, Gorayeb R, Liberatore Junior RDR, Domingos NAM. Depressão, ansiedade e competência social em crianças obesas. Estud Psicol (Natal). 2005;10(1):35-9. doi: 10.5935/2238-3182.20130012.

32. Souza JMB, Castro MM, Maia EMC, Ribeiro NA, Almondes KM, Silva NG. Obesidade e tratamento: desafio comportamental e social. Rev Bras Ter Cogn. 2005;1(1):74102. Disponível em: http://pepsic.bvsalud.org/scielo. php?script=sci_arttext\&pid=S1808-56872005000100007.

33. Fernandes MH. Um corpo para dois. In: Fernandes MH.

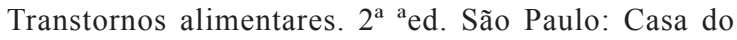
Psicólogo; 2007.

34. Godoy EHM. Histórias da vivência sexual de mulheres submetidas à cirurgia da obesidade [Dissertação]. Ribeirão Preto: Faculdade de Filosofia, Ciências e Letras de Ribeirão Preto da USP; 2008.

35. Narvaz M, Oliveira LL. A relação entre o abuso sexual e transtornos alimentares: uma revisão. Interam J Psychol. 2009;43(1):22-9. doi: 10.1080/00224490609552300.

36. Vasconcellos SC, Sepúlveda KR. Obesidade mórbida: um corpo em evidência e em desamparo. Rev SBPH. 2011;14(1):92-111. doi.org/10.1590/S1516444620000000222000 .

37. Garcia FSFC. Um corpo que sofre: um caso clínico de obesidade na adolescência. Contemporânea Psicanal 
Teodoro PP. Investigação dos padrões relacionais do vínnculo mãe-filha envolvidos na obesidade feminina.

Transdisciplinaridade (Porto Alegre). 2011;(12):130-58. Disponível em: http://www.revistacontemporanea.org.br/ site/wp-content/artigos/edicao12_Um_Corpo_que_Sofre. pdf.

38. Winnicott DW. Os bebês e suas mães. 4a ed. São Paulo: Martins Fontes; 2013.

39. Dalgalarrondo P. Psicopatologia e semiologia dos transtornos mentais. 2a ed. Porto Alegre: Artmed; 2008.

40. Mc Dougall J. As múltiplas faces de Eros. São Paulo: Martins Fontes; 1995.

41. Craig PL, Truswell AS. Dynamics of food habits of newly married couples: weight and exercise patterns. Aust J Nutr Dietet. 1990;47:42-6. http://dx.doi.org/10.1590/S01006991200900040055000 .

42. Gomes FKTM, Dezan SZ, Barbieri V. "Não pode!": a função paterna e a obesidade infantil. Psicol Rev. 2014;45(2):176-86. http://dx.doi.org/10.1590/S01006991200900040055000.

43. Dixon SD, Levine RA, Brazelton TB. Malnutrition: a closer look at the problem in east african village. Dev Med Child Neurol. 1982;24:670-85. http://dx.doi.org/10.1590/S010069912009000400008 .

44. Azevedo MASB, Spadotto C. Estudo psicológico da obesidade: dois casos clínicos. Temas em Psicologia da SBP. 2004;12(2):127-44. http://dx.doi.org/10.1590/S010279722005000100006.

45. Motta EF. O peso da obesidade: o excesso de peso como sintoma [Internet]. Psicologado. 2011 [citado 23 fev. 2016]. Disponível em: https://psicologado.com/abordagens/ psicanalise/o-peso-da-obesidade-o-excesso-de-peso-comosintoma.

46. Sedeu RL. Da toxicomania à adicção: uma abordagem relacional. Estud Psicanal. 2014;(42):107-20. http://dx.doi. org/10.1590/S0103-166X2007000400008.

47. Nakasu MVP. Desejo de se fazer mal ou escravo de uma só solução? A qual dessas duas proposições estaria ligada a economia psíquica da adição? Ciênc Humanas Rev. 2006;4(1):41-8. http://dx.doi.org/10.1590/S141381232011001300025 .

48. Alves D, Pinto M, Alves S, Mota A, Leirós V. Cultura e imagem corporal. Motricidade. 2009;5(1):1-20. Disponível em: http://www.revistamotricidade.com/arquivo/2009_ vol5_n1/v5n1a02.pdf.

49. Tavares TB, Nunes SM, Santos MO. Obesidade e qualidade de vida: revisão da literatura. Rev Med Minas Gerais. 2010;20(3):359-66. http://dx.doi.org/10.1590/S010442302010000200014 .

50. Sopezki D, Vaz CE. O impacto da relação mãe-filha no desenvolvimento da autoestima e nos transtornos alimentares. Interação Psicologia. 2008;12(2):267-75. http:// dx.doi.org/10.1590/S1413-73722010000200007.

51. Machado MG. A obesidade para o obeso: uma leitura psicanalítica [Dissertação]. Belo Horizonte: Pontifícia Universidade Católica de Minas Gerais; 2011.

52. Moliner J, Rabuske MM. Fatores biopsicossociais envolvidos na decisão de realização da cirurgia bariátrica. Psicol Teor Prat. 2008;10(2):44-60. http://dx.doi.org/10.1590/S0080623420140000700002 . 